\title{
Red Meat Consumption
}

National Cancer Institute

\section{Source}

National Cancer Institute. Red Meat Consumption. NCI Thesaurus. Code C20046.

A risk factor for colorectal, stomach, and pancreatic cancer. 